\title{
e-Navigation and situation-dependent manoeuvring assistance to enhance maritime emergency response
}

\author{
Michael Baldauf • Knud Benedict • Sandro Fischer • Michael Gluch • \\ Matthias Kirchhoff • Sebastian Klaes • Jens-Uwe Schröder-Hinrichs • \\ Dana Meißner • Ullrich Fielitz • Erland Wilske
}

Received: 17 August 2011 /Accepted: 14 September 2011/Published online: 14 October 2011

(C) World Maritime University 2011

\begin{abstract}
Safe ship handling in every situation and under all prevailing circumstances of ship status and the environment is a core element contributing to the safety of the maritime transportation system. Especially in case of emergencies, there is a need for quick, accurate and reliable information to manoeuvre a ship safely. This paper focusses on investigations into enhanced response to maritime emergencies by means of onboard manoeuvring support. The research and discussions are done exemplarily for person overboard $(\mathrm{PoB})$ accidents. $\mathrm{PoB}$ is a typical situation for application of manoeuvring assistance and decision support, e.g. in order to return quickly to the position of the accident. Based on the analysis of selected accident case studies and existing solutions representing the technical stateof-the-art, shortcomings will be identified and discussed, and a potential approach for advanced manoeuvring support in the context of e-Navigation-based requirements will be introduced and discussed.
\end{abstract}

Keywords e-Navigation · Fast time simulation · Situation dependent manoeuvring assistance $\cdot$ Person overboard

A substantially shorter version of this paper was presented at the 9th International Symposium on "Marine Navigation and Safety of Sea Transportation" in Gdynia, June 20 (Baldauf et al. 2011b)

M. Baldauf $(\bowtie) \cdot$ S. Klaes $\cdot$ J.-U. Schröder-Hinrichs

Maritime Risk and System Safety (MaRiSa) Research Group, World Maritime University, Citadellsvägen 29, P.O. Box 500, 20124 Malmö, Sweden

e-mail: mbf@wmu.se

K. Benedict $\cdot$ S. Fischer $\cdot$ M. Gluch $\cdot$ M. Kirchhoff

Institute for Ship Theory, Simulation and Maritime Systems (ISSIMS), Hochschule Wismar, University of Applied Sciences: Technology, Business and Design, R.-Wagner-Str. 29, 18119

Rostock, Germany

D. Meißner • U. Fielitz

Institut für Sicherheitstechnik/Schiffssicherheit, F.-Barnewitz-Str. 3, 18119 Rostock, Germany

E. Wilske

SSPA Sweden AB, Chalmers Tvärgata 10, Box 24001, 40022 Gothenburg, Sweden 


\section{Introduction}

Maritime operational risk management in shipping deals with the avoidance of accidents in general. When navigating a ship from port of departure to port of destination, each operational risk of an accident and hazardous event, respectively, has to be evaluated continuously in order to recognise situations with risks developing above the accepted level in time and to react accordingly and to reduce such operational risks so that they are in the range of an acceptable risk level.

The most important operational risks in maritime transportation are groundings and collisions. The third frequent risk in shipping with regard to casualty frequencies is fire and explosions. Far more seldom are person overboard (PoB) accidents.

However, in safety sciences from an engineer's point of view, risk is clearly defined as a combination of the frequency of a hazardous event and its consequences, preferably expressed in monetary units. Consequently, because in almost three out of four cases of a person overboard accident, the person fallen overboard finally dies, the risk of this category of accidents is on a very high level.

Therefore, it is worth seeking and researching potential solutions which contribute to the minimization of the frequency of rescue operations failing and reducing the consequences. From literature, it is known that in cases of a person falling overboard, it is essential to recognise the situation as soon as possible and to alert the navigators on the bridge immediately in order to bring the ship as quickly as possible back, or at least as close as possible to the position of the accident, or on an opposite course to search for the missing person. Relevant manoeuvres and means to support manoeuvring have been often discussed in literature; see, e.g. Benedict and Hilgert (1986a, b)

The detection in-time of a PoB accident strongly depends on careful observations by each crew member but cannot be carried out completely and comprehensively at all times. That is why suitable methods and equipment supporting the automatical and timely detection of such an event can help to reduce the probability of fatality. However, until now such solutions are nonexistent or at least not in use yet.

On the other hand, when the accident is registered quickly and the alarm and the life ring with position indicator released, then it is crucial to keep a sharp lookout and keep in contact with the person in water and to manoeuvre the ship back as quickly as possible and rescue the person before he/she is affected by hypothermia. One challenge for manoeuvring is to find the optimal steering sequence of rudder and engine commands under the prevailing circumstances of the ship status and the environment. Again, technical solutions, which automatically generate the steering sequence for the optimal manoeuvre, do not exist yet and the navigator depends heavily on his knowledge and manoeuvring experiences. This paper introduces results of ongoing research into the present situation regarding PoB accidents and potential further developments to improve the probability of successfully rescueing a person fallen overboard by improving the detection of the accident and supporting the quick generation of an appropriate manoeuvring plan for the return manoeuvre. 


\section{Investigations into the present situation of person overboard accidents}

\subsection{Requirements for automatic detection of a person falling overboard}

Even today, the prompt detection of a person falling overboard is a challenging task. On merchant ships, mariners' life jackets are increasingly equipped with sophisticated small location systems actively transmitting the position. In the instance of a person overboard accident, the person can be localized more easily. On passenger ships, as on ferries or cruise liners, the problem is more complicated because passengers do not wear life jackets nor any detection systems. On the other hand, the overall number of $\mathrm{PoB}$ accidents is increasing, i.e. because of the increasing number of cruise ship passengers. Nowadays, on modern cruise ships, the decks and ship sides are monitored by using surveillance cameras. Nevertheless, PoB accidents are often not recognised because the permanent and uninterrupted observation of the monitors is not possible. That is why a concept for a technical solution for the automatic detection of $\mathrm{PoB}$ accidents needs to be developed. The fundamentals for the concept will be derived from the following principal analysis of:

1. What are the characteristic elements of a typical PoB emergency?

2. Which requirements have to be fulfilled by an automatic detection system?

To answer these principal questions, a thorough investigation of 144 data sets of PoB accidents at cruise ships was performed. The main results from this analysis can be summarized as follows:

- Within the 144 cases, 149 persons were affected, whereof 29 have been crew members.

- Only 31 persons of these 149 could be rescued.

- In only 81 cases, the concrete time or at least a time range was given for the time the accident happened. In approximately $30 \%$ of these cases, the time was determined after that accident, e.g. by analysis of recorded video data. This means that in most cases, the accident was not recognised in time or even not recognised at all.

- With respect to the ship-related position of the PoB accidents, it was analysed that they occurred along the whole outer ship range. However, there seems to be an accumulation of cases, where the victims fell from the balconies of cruise liners.

- The major portion of the analysed PoB accidents happened during the night between 2200 and 0200 hours the next day (see also Fig. 1).

According to these results and considering the external conditions onboard ships at sea, the following basic requirements for an automatic detection system can be derived:

- Immediate and automatic detection of a falling person

- Avoidance of false alarm, by reliable distinction between a falling person and other falling objects

- Continuous operation during night and daytime

- Robust resistance against disturbances caused by weather and vibration 


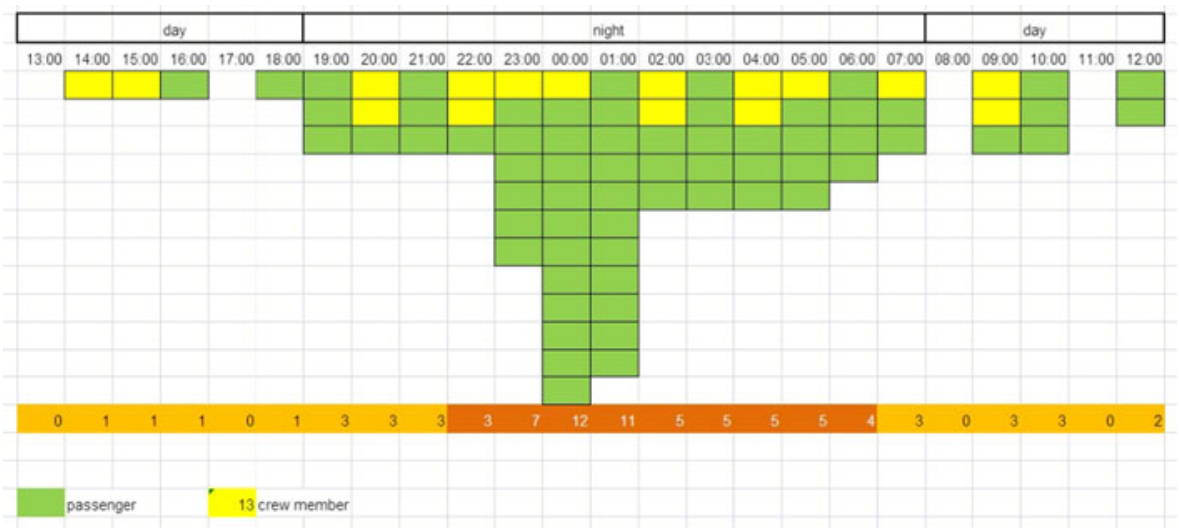

Fig. 1 Results of analysis of person overboard accidents on cruise ships (data collected from Federal Bureau of Maritime Casualty Investigation, Germany; Transportation Safety Board of Canada, Memorial University of Newfoundland; Marine Accident Investigation Branch, UK; www.janmaat.de, Tim Schwabedissen, DE)

- When of using any kind of electromagnetic waves: no disturbance by the ships, navigation systems and vice versa

- Reasonable costs of investment, operation (e.g. power consumption) and maintenance

- Easily handled by the crew

- Ensuring data privacy protection

For the purposes of feasibility studies, there are ongoing investigations into different technological approaches and techniques, respectively. The following potential solutions will be evaluated and tested, as they could provide a profound technical basis for the detection system, e.g.

- Camera surveillance in combination with connected night-vision equipment

- Thermographic camera

- Radar technique

Presently extensive field tests are under preparation. The field tests are to generate performance data to identify the advantages and disadvantages of each the single techniques. Based on comparative analysis, recommendation will be derived for one or a combination of the techniques.

\subsection{Person overboard case studies in merchant shipping}

The first case considers a fully laden containership on a voyage from the port of Rotterdam to a port in the Baltic Sea. The actual speed was reduced due to deteriorating weather conditions with strong winds and increasing wave heights. Some bunker room alarms occurred during the night, and the ship command decided to send a team to investigate the situation and the source of alarms.

A team of two engineers went to the bunker room between the cargo holds, but one of them was hit by a wave and washed overboard. Although his immersion suit 
was without a floating device, it kept him warm, and a fender which had been torn loose kept him afloat.

The ship's command immediately informed shore-based traffic centre and requested assistance but decided not to conduct a return manoeuvre such as a SCHARNOW or WILLIAMSON Turn. As documented in the official accident investigation report, the ship continued her voyage without any change of course or speed (Fig. 2). Happily, the person overboard was rescued several hours later by a search and rescue (SAR) vessel and brought to a hospital, where he recovered and was able to resume his work a few days later.

The second sample is focussing on a container ship en route from Mexico to Japan during the winter season. The ship's route had to lead through a sea area behind a typhoon. However, the average wind condition during the time of the accident was Bft 5 with a corresponding sea state and with significant wave heights of approximately $5 \mathrm{~m}$. In the sea area $300 \mathrm{~nm}$ off the Japanese coast, a team of four crew members performed various tasks on the bow. In the course of their work, several strong waves washed over the deck, hitting three seamen and sweeping overboard one of the mariners (Fig. 3).

According to the official accident investigation report, which also includes an analysis of the manoeuvre log and Electronic Chart Display and Information System (ECDIS) records, there were no manoeuvres in compliance with or even similar to one of the known return manoeuvres to bring the ship back to the accident's position, or on a opposite course along the original track. While some crew members attempted resuscitation, others were involved in search measures initiated by the ship command. The resuscitation efforts in connection with the seriously injured mariner were unsuccessful. Darkness started to fall as early as 1700 hours. Although there were supporting search efforts by Japanese Coast Guard (JCG) aircraft, the mariner who had been gone overboard could not be found. In addition at around 2100 hours,

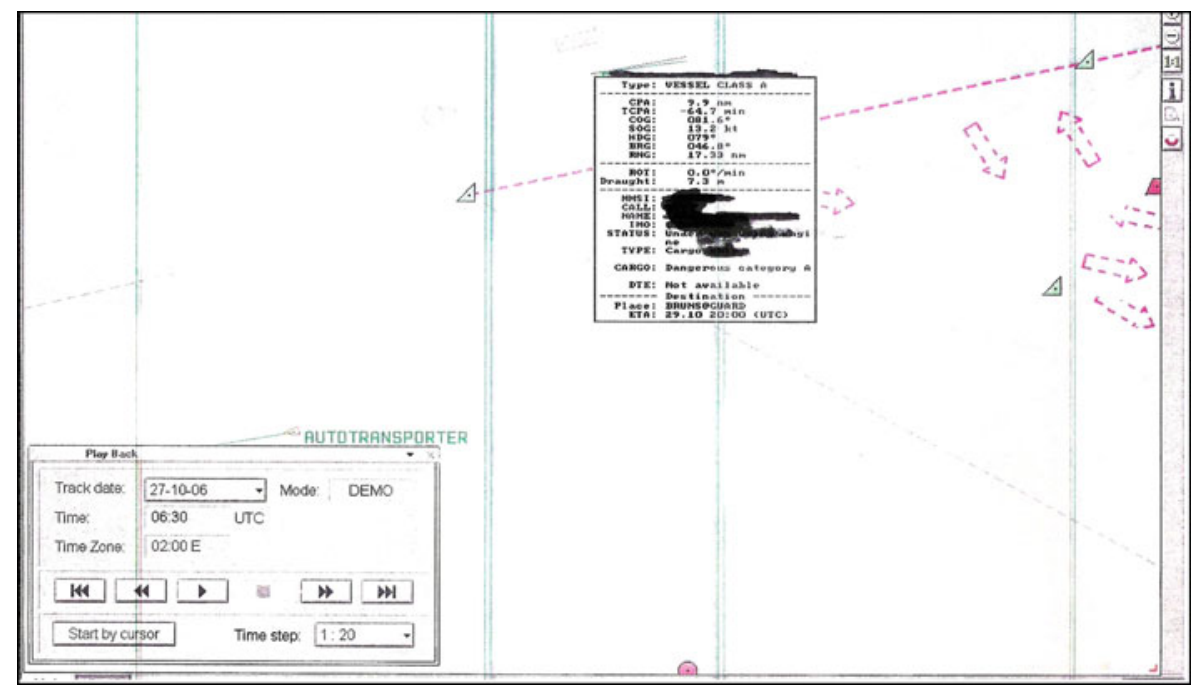

Fig. 2 Snapshot from ECDIS record - continuation of the voyage without conducting any manoeuvre (taken from accident investigation report) 


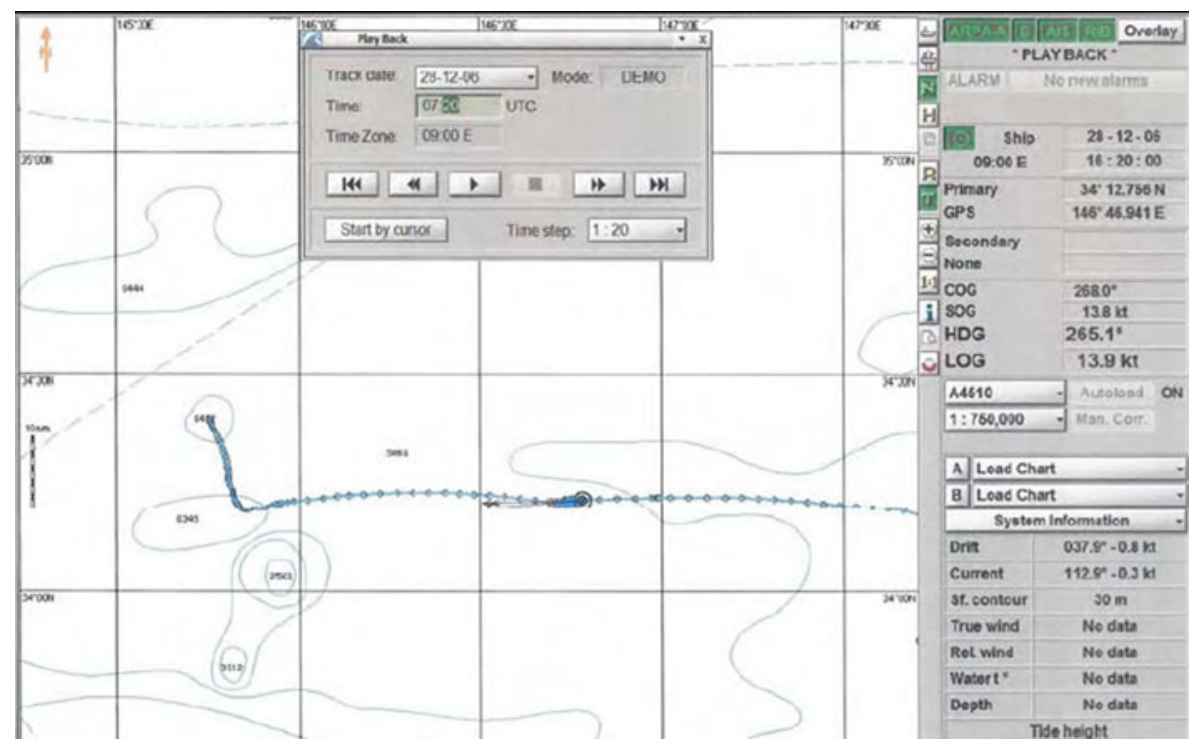

Fig. 3 Manoeuvre track during person overboard accident (taken from official accident investigation report)

rain began to fall. The search was ultimately suspended $6 \mathrm{~h}$ after the accident due to continuously deteriorating weather and resumed the next day by the JCG.

The vessel finally continued its journey to Japan, where two injured mariners recovered in hospital. The mariner who had been swept overboard was unfortunately never found.

\section{Rules, procedures and equipment}

As demonstrated in the cases studies above, even today a PoB accident in most cases unfortunately ends with the death of the concerned person. Available statistics from national Marine Accident Investigation branches all over the world show that in up to $75 \%$ (see, e.g. Annual Marine Incident Report 2003, Queensland) of such cases, a mariner or passenger overboard finally died. Several publications refer to an average number of 1,000 dead worldwide per year due to PoB accidents. According to the latest information about just only North American passenger shipping companies, compiled by KLEIN for the period from 2000 to 2010, about cruise and ferry passengers and crew overboard accidents there were over 150 PoB accidents.

Compared to groundings and collisions, person overboard accidents are rarer events, but in terms of risk assessment have much greater consequences. A PoB accident requires immediate decision making and prompt action. Every second is important and influences the success of the actions to rescue the person overboard. With regard to the causes of such accidents and the involvement of factors related to the human element, it is assumed that, similar to other investigated cases (see Schröder-Hinrichs et al. 2011), data extracted from available reports are not 
sufficient to verify the situation. Standard plans, as exemplarily shown in Fig. 4, are available which can be visualised, e.g. as flow chart diagram according to Hahne (2006).

However, the poor success rate of rescue actions begins already with the difficulty of noticing and recognising the hazard immediately. The first task of the bridge team is to mark the position, release a life ring with safety buoy (smoke and light signal), keep a sharp lookout and turn the ship back to the position of the accident to pick up the person overboard.

The crucial action is to bring the ship back to the position of the accident. In literature, several manoeuvres for person overboard accidents are described. However, there is no single standard procedure recommended, as the effectiveness of a manoeuvre depends on the type of the ship and the prevailing circumstances of the particular situation. The guidance given therefore basically takes into account only the amount of time passed after the accident. According to the International Aeronautical and Maritime Search and Rescue/Merchant Ship Search and Rescue

Fig. 4 Sample of a person overboard action plan addressing actions of witness, captain and members of the bridge team (according to Hahne 2006)

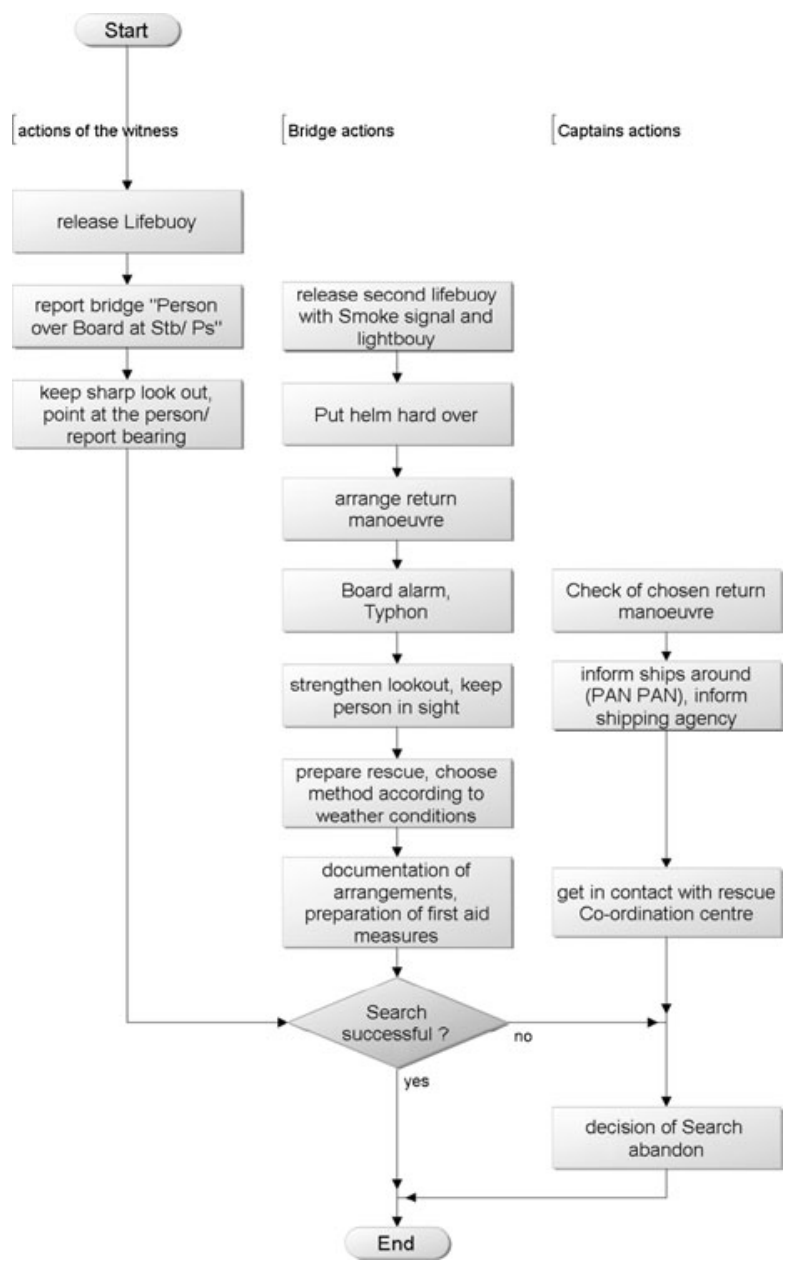


(MERSAR) manual, firstly published by International Maritime Organization (IMO) in 1970, threefold action cases for manoeuvring are described:

- "Immediate action" situation

- "Delayed action" situation

- "Person missing" situation

Referring to the experiences and proven effectiveness in many person overboard casualties, the SINGLE Turn, the WILLIAMSON Turn as well as the so-called SCHARNOW Turn are mentioned in the MERSAR manual. An analysis was made for selection of the optimal type necessary in real situations and has shown that the WILLIAMSON Turn, which applied most often, is actually not the best option in most cases. Often, the best option if a certain time has elapsed is the SCHARNOW Turn, while if the accident was noticed immediately, the best option is often the SINGLE Turn. Clear advantages of a combination of SCHARNOW and SINGLE Turns were seen because both manoeuvres are identical up to course change of $220^{\circ}$, and therefore, more time is available and a later decision is possible for final manoeuvre. Furthermore, a saving of time is possible because the manoeuvring procedure is faster. Finally, these turns provide better conditions for lookout because the turning direction does not change and the smaller distances to initial position support better eye contact, even in restricted visibility (Fig. 5).

However, there are further turns which are rarely used in commercial shipping as knowledge and/or experience is limited. In case of real accidents, almost no experience is available for most of the ship officers; they have never or seldom experienced such an accident personally.

The mandatory training procedures, including the conduct of return manoeuvres, are normally executed under good conditions in order to keep a safe environment for the persons involved in the training routine. Contrary to this, in accidents, the conditions, especially wind and waves, are worse. Action plans according to the International Safety Management Code are available, but in the case of real

Fig. 5 Comparison of the three main types of recommended person overboard manoeuvres

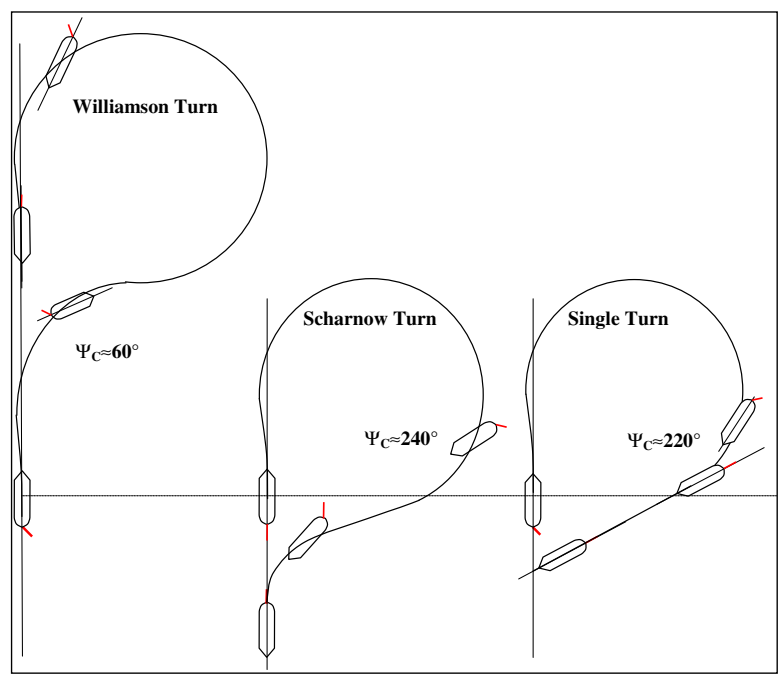


situations, the use of these plans is often limited because plans are made to give more general guidance. No technical means, or no suitable ones, are available, e.g. for the immediate selection and planning of the manoeuvre in the respective situation.

Today, ECDIS and GPS or other off-the-shelf systems are available, often integrated into integrated navigation and bridge systems (INS/IBS), and allow for marking the position of an accident electronically. However, it still has to be done manually. As accident investigations have shown, in such stressful situations, the crew member may fail to do so.

Most Radar/ECDIS equipment available on the market (i.e. Transas NaviSailor or Furuno ECDIS EC 1000) allows for the display of a marked position and may provide information about distance and "time to go" to the marked position on the basis of standard calculation using actual course/speed information. Some more enhanced systems (e.g. latest Visionmaster FT systems of Sperry Marine) even allow for the display of search patterns - but this is needed later if the immediate measures for finding the person right after the accident have failed.

The consideration of external factors, such as wind influence on the ship's track, is possible only on the basis of the mental model of the ship officer on watch; no computer-based support is available when it is most urgently needed. Like all other maritime accidents, person overboard and search and rescue cases are rare events. Immediate actions are necessary and have to take into account the prevailing circumstances of the environment and the manoeuvring characteristics of the ship. The general guidelines and information for manoeuvring have to be adapted to the actual situation. However, the manoeuvring data displayed on paper on the bridge to assist the captain and navigating officers are of a general character only and of limited use in the case of real accidents. Manoeuvring assistance regarding optimised conduction adapted to the specific hydrodynamic and the actual environmental conditions is urgently needed.

Although new and highly sophisticated equipment and INS/IBS have great potential to provide enhanced assistance, situation-dependent manoeuvring information and recommendation are not available yet. The same is valid for SAR actions. Optimisation and coordination of the actions and of all involved parties is needed, taking into account e-Navigation-related concepts. Finally, the related training courses need to be enhanced, especially by means of the use of full-mission shiphandling simulation facilities.

\section{4 e-Navigation and manoeuvring assistance}

\subsection{The e-Navigation concept}

After a long period characterized by rapid developments of new technical equipment like, e.g. ECDIS or automatic identification systems and its introduction into shipping to support and improve the safety of navigation, a new trend can be seen. Nowadays, starting from the performance standards for INS and IBS (see IMO 2007 and IMO 2009), new systems have to be integrated into existing systems to provide the complete range of benefits and potential to the navigator on a ship's bridge. The 
most important initiative dedicated to these aspects is the e-Navigation initiative of IMO and International Association of Marine Aids to Navigation and Lighthouse Authorities (IALA). This initiative takes into account the technological developments and other ongoing initiatives related also to legal and organisational frameworks, as e.g. the e-Maritime initiative (see, i.e. Graff 2009 for further information) to improve maritime safety and offer in general a wide range of new possibilities for sophisticated solutions.

According to the definitions given by both the organisations, e-Navigation is the harmonised collection, integration, exchange, presentation and analysis of maritime information onboard and ashore by electronic means to enhance berth-to-berth navigation and related services, for safety and security at sea and protection of the marine environment. From this definition, it becomes clear, that e-Navigation is a concept trying to integrate all actors, stakeholders, manufacturers and all other participants in the maritime transportation process. As sketched in Fig. 6 (a modified picture, originally developed by and taken from Motz et al. 2011), the concept is also addressing all the technical systems in use onboard and ashore and their appropriate communication to support safe and efficient transportation in the maritime field (more detailed explanations are given by Weintritt 2010).

Consequently, within this concept, new approaches to provide advanced manoeuvring support in cases of maritime emergencies can be developed as, e.g. for onboard manoeuvring support and assistance for the specific case of PoB accidents. Among others motivated by the introduction of new information and communication technologies and their potentials for more sophisticated solutions, these research and development is undertaken taking also into account the latest e-Navigation initiative of IMO and IALA.

\subsection{Selected aspects of manoeuvring}

In principle, manoeuvres can be divided into routine manoeuvring and manoeuvring in safety-critical and emergency situations. This division can be further developed by considering different sea areas where manoeuvres have to be performed, e.g. in open seas, in coastal waters and fairways as well as in harbour approaches and basins. Routine manoeuvring in open seas includes ship handling under normal conditions, e.g. in order to follow a planned route from the port of departure to the port of

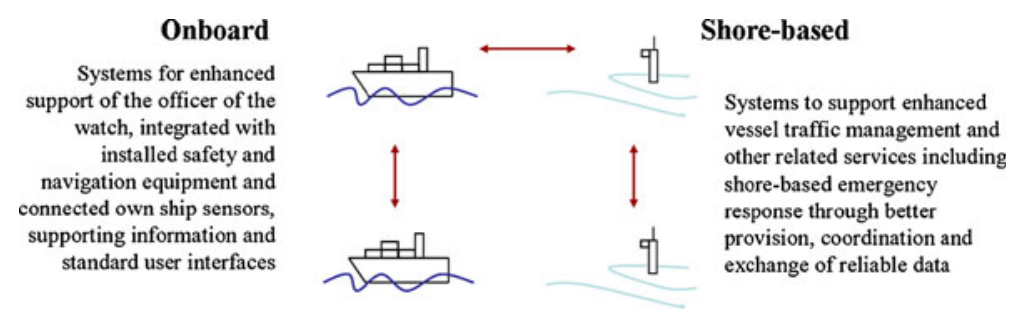

Communication

infrastructure providing authorized seamless information transfer

Fig. 6 Principle elements of e-Navigation 
destination. Such manoeuvres are, e.g. simple course changes, speed adaptations according to the voyage plan etc.

Manoeuvring in coastal areas, at entrances to ports and in harbour basins include manoeuvres, e.g. to embark and disembark a pilot, to pass fairways and channels and even berthing manoeuvres with or without tug assistance. Manoeuvring in safetycritical and emergency situations deals with operational risk management and includes manoeuvres to avoid collision or grounding, to avoid dangerous rolling in heavy seas or to manoeuvre in the case of a real accident, e.g. return manoeuvres in case of a person overboard accident or when involved in search and rescue operations.

Taking the case studies described in the second section, it can be concluded that there is a strong need to improve and support the ship command with more sophisticated situation-dependent manoeuvring information, especially in an emergency. It is worthwhile to use the potential of e-Navigation and the related new technology in order to generate such assistance to the human operator when a person has fallen overboard.

\subsection{Situation-dependent manoeuvring assistance by dynamic wheelhouse poster and electronic manoeuvring booklet}

As earlier investigations into the field of collision and grounding avoidance have shown, there is an unsatisfactory exchange of such information already available on a ship's navigational bridge from different sensors and sources. Until today, the change of manoeuvring characteristics, e.g. with respect to their dependencies on speed and loading conditions, as well as on environmental conditions (e.g. water depth, wind and current), has not yet been sufficiently considered. Highly sophisticated INS (see also IMO 2009) are installed on board but do not provide the bridge team with situation-dependent manoeuvring data, e.g. turning circle diameter, stopping distances etc. for the actual situation. This kind of information is not only needed in case of $\mathrm{PoB}$ accidents but also for enhanced operational risk management and the application of situation-dependent alarm thresholds for triggering collision warnings (Baldauf et al. 2011a).

However, the ongoing developments under the IMO's and IALA's e-Navigation initiative with the application of new technologies and data might allow exactly this in the future. In the context of the e-Navigation concept and its definition, the introduction of a dynamic wheelhouse poster and an electronic manoeuvring booklet are suggested. Up-to-date manoeuvring information adapted to specific purposes and situations can be provided by using enhanced integrated simulation technologies.

For that purpose, a first generic concept (Fig. 7) has been drafted to combine own ship status and environmental information from different sensors and manoeuvring information that, e.g., could be gained via a mandatory Voyage Data Recorder or from ECDIS recordings (Weintrit 2003). For a person overboard accident, the mandatory wheelhouse poster should contain information about return manoeuvres. Spotlight analyses have shown that in most cases, this information is incomplete and only partly or not available in the documents, even for the basic cases of deep and shallow waters as well as for loaded and ballast conditions. 


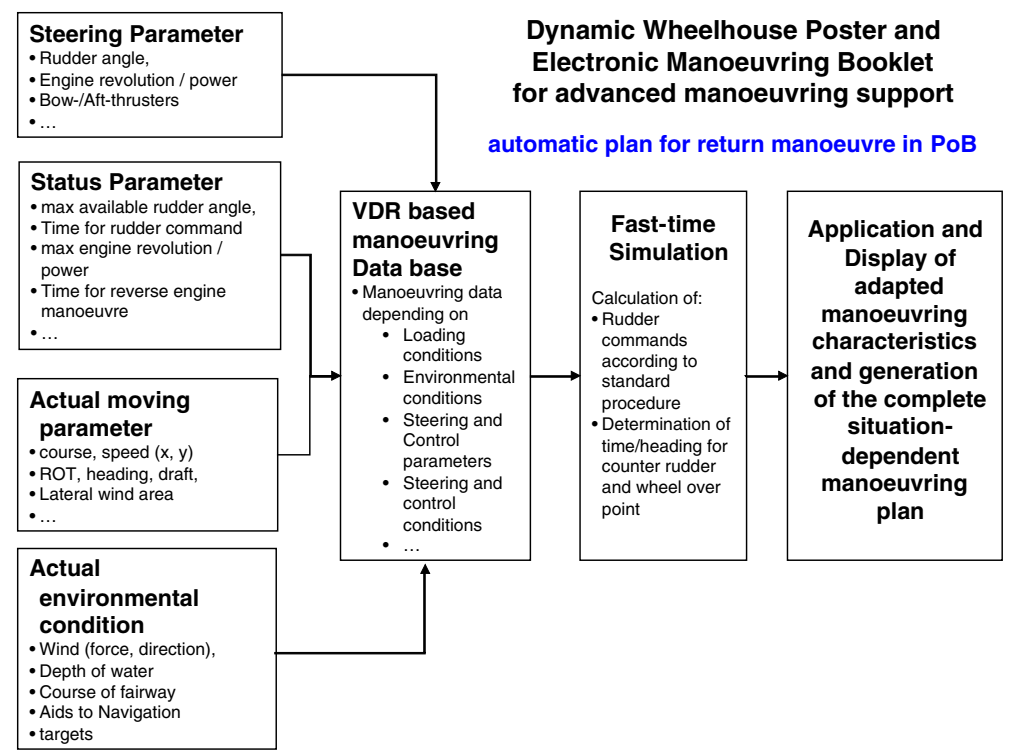

Fig. 7 Principal structure and dataflow for generating a dynamic wheelhouse poster and manoeuvring booklet to provide a situation-dependent support for return manoeuvre

\subsection{Application of fast-time simulation techniques for manoeuvring assistance}

The core element of the concept for situation-dependent manoeuvring support is the application of fast-time simulation technologies developed by Benedict et al. (2006a, b) and applied for several purposes (Baldauf et al. 2011a) and (Benedict et al. 2009).

The following equation of motion is used as the model for the ships dynamic and implemented in software modules for fast-time simulation:

$$
\begin{aligned}
& X=m\left(\dot{u}-r v-x_{\mathrm{G}} r^{2}\right) \\
& Y=m\left(\dot{v}+r u+x_{\mathrm{G}} \dot{r}\right) \\
& N=I_{z} \dot{r}+m x_{\mathrm{G}}(\dot{v}+r u)
\end{aligned}
$$

On the right side are the effects of inertia where $u$ and $v$ represent the speed components in longitudinal and transverse direction $x$ and $y$ and $r$ is the rate of turn of the ship. The ship's mass is $m, x_{\mathrm{G}}$ is the distance of the centre of gravity from the origin of the coordinate system and $I_{z}$ is the moment of inertia around the $z$-axis. The ship's hull forces $X$ and $Y$ as well as the yawing moment $N$ around the $z$-axis are on the left side. Their dimensionless coefficients are normally represented by polynomials based on dimensionless parameters, for instance in the equation for transverse force $Y$ and yaw moment $N$ given as the sum of terms with linear components $N r, N_{v}, Y_{r}$ and $Y_{v}$ and additional nonlinear terms. Other forces, such as rudder forces and wind forces, are expressed as lookup tables. There are additional equations for the engine model and also lookup tables to represent automation systems characteristics. The solution of this set of differential equations is calculated every second; some internal calculations are even done at a higher frequency. Further detailed descriptions can also be found, e.g. in Baldauf et al. (2010).

The inputs for the simulation module consist of controls, the states and the data for the environmental conditions. Additionally, there is an input of the ship's 
condition parameters. They are normally fixed, but in case of malfunctions, they might change, e.g. reducing the rudder turning rate or maximum angle. The results from the simulation module are transferred to be stored or directly displayed on demand in the dynamic wheelhouse poster or the electronic booklet.

The module is used to perform calculations to predict the path for specific actual or planned commands. In this way, the module can be applied to plan and optimise the return manoeuvre and automatically produce the complete situation-dependent manoeuvring plan for a return manoeuvre.

\section{Situation-dependent manoeuvring planning for return manoeuvre}

\subsection{Aim and objective of the planning process}

The objective of the simulation-based manoeuvre planning and optimisation process is to find a suitable procedure which can be used in a particular situation for the actual status of a real ship. There are standard files for manoeuvre control settings for simulating specific manoeuvres. By means of the fast-time simulations, various results of manoeuvres will be generated. The final goal is to achieve the sequence for an optimised manoeuvre control setting adapted to the actual situation parameter. Presently, the biggest problem is that there are many options possible, and the effect of the changes of the parameters used in the models is not very clear; some changes may even have effects which counteract the results of the others. Therefore, it is very important to know which parameters which have a clear impact on the manoeuvring characteristic. An example is given in the following section to indicate the need and the effect of manoeuvring optimisation by means of an Emergency Return Manoeuvre.

\subsection{Planning and conduction of an emergency return manoeuvre}

Although planning and conduct of a manoeuvre seems to be a minor and academic exercise, the problem is well recognised and addressed from experienced practitioners (Lloyd 2007a, b) and (Jutrovic 2010) too. Comprehensive and thorough preparation of a necessary return manoeuvre is essential for the successful rescue of a person overboard. The concrete example discussed hereafter is the emergency return manoeuvre using the well known "SCHARNOW Turn" (Fig. 8).

As with all other emergency return manoeuvres, the fundamental aim is to return the vessel to the original track by the shortest route and with minimum loss of time. In practice, the vessel initially follows the turning circle and after shifting the rudder by a course change of about $240^{\circ}$ finally turns to counter rudder and amidships. The vessel then swings back to the opposite course at a certain measurable distance from the original track, at a certain distance from the reference manoeuvre.

The first problem is how to get the "Optimal reference manoeuvre" because the heading change of $240^{\circ}$ is an average only and can differ among ships from $225^{\circ}$ up to $260^{\circ}$ or even more, as can the WILLIAMSON Turn which can vary from $25^{\circ}$ to $80^{\circ}$ instead of the standard average value of $60^{\circ}$. Figure 9 demonstrates the wide variety of the outcome of the standard course of rudder commands compared for an 
Fig. 8 Reference outline for the SCHARNOW Turn

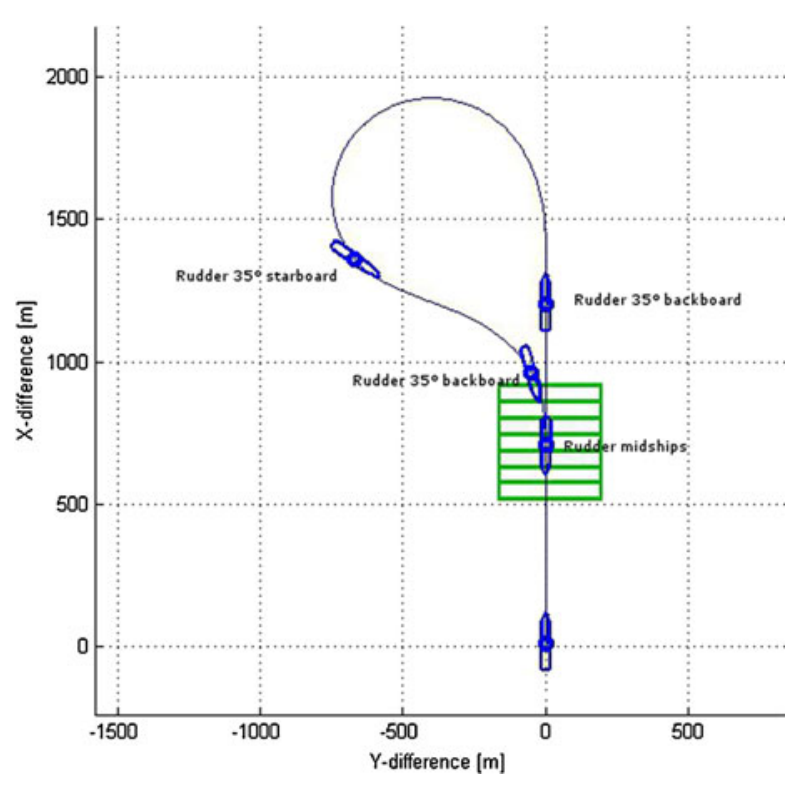

8.100-TEU container vessel (purple), a RoRo passenger ferry (blue), a 2.700-TEU container feeder vessel (red), and a tanker (green).

Beside this basic variance according to the ship type, there are other more important dependencies that have a substantial impact on the outlined path of a return manoeuvre. Further examples are given in Fig. 10, which demonstrate the dependency of the final outcome of the return manoeuvre on the loading condition

Fig. 9 Comparison of the outline of standardized SCHARNOW Turn for four different types of ships

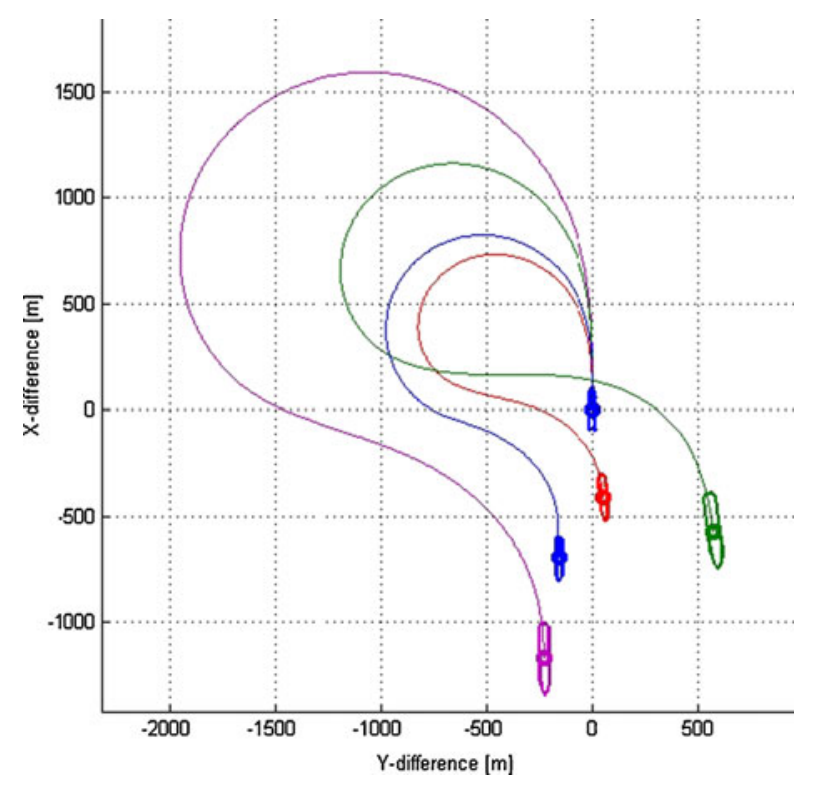


Fig. 10 Comparison of the outline of standardized SCHARNOW Turn for an 8.100-TEU container ship in ballast condition for three different wind conditions (no wind (blue) and wind Bft 6 from north (green) and northwest (purple), respectively)

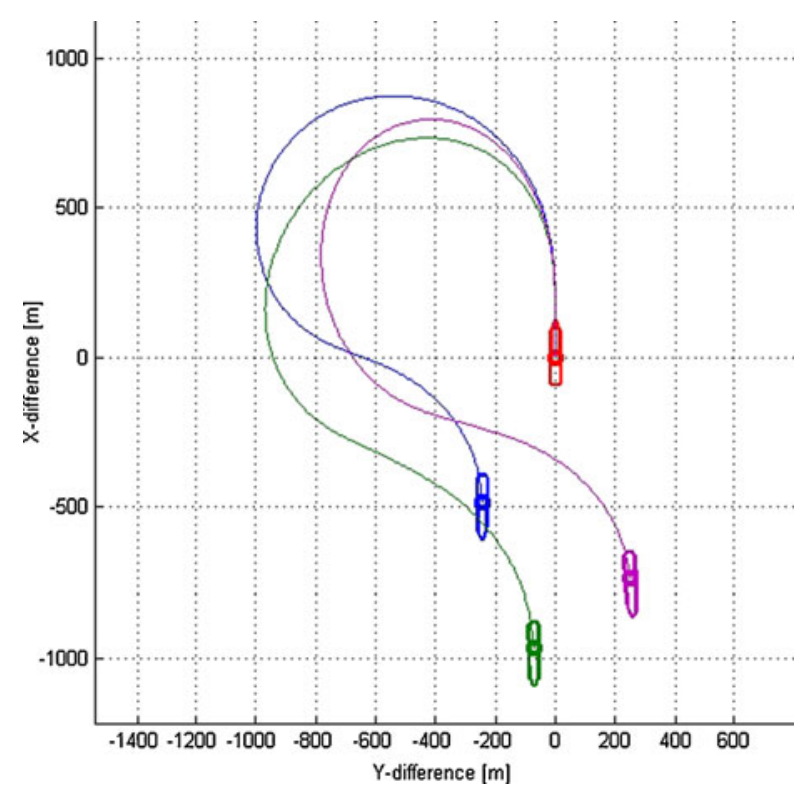

as well as on the wind force and wind direction. Of course, the outline would change again if the ship is fully laden or if shallow water effects occur.

Finally, it should be mentioned that there are dependencies on the initial ship speed and on the available water depth. It is clear to be seen that adaptation of the manoeuvre plan has to be performed for each single varied situation parameter. On the other hand, the simulation software module is able to provide the corresponding data accordingly. The next step after having simulated the standard manoeuvre procedure for the prevailing environmental circumstances is then to determine the best manoeuvre sequence.

Using the simulation software module, there are two principal ways available in order to determine the optimal sequence for the situation-dependent manoeuvre plan:

- The first option is to simulate series of manoeuvres using standard "SCHARNOW Turn" (or WILLIAMSON Turn) manoeuvring commands in automated simulation series. This method can be seen in Fig. 11, where several heading changes were used as parameters to vary the final result of the distance between the initial track and the return track.

The results presented in Fig. 11 are for the 8.100-TEU container ship in ballast conditions and taking into account northwesterly winds of Bft 6 .

- The second option is to start with a standard "SCHARNOW Turn" manoeuvre command series for automated simulation, combined with an optimisation procedure (Fig. 12).

A bi-criterial optimisation algorithm is used to find the suitable heading change for counter rudder as a parameter to achieve the smallest distance (limit $=10 \mathrm{~m}$ ) between initial track and return track on opposite heading (limit $\left.=2^{\circ}\right)$. The optimal track is 
Fig. 11 Optimisation of an emergency return manoeuvre by series with different heading changes from $200^{\circ}$ up to $270^{\circ}$ (with increasing steps of $10^{\circ}$ ) for counter rudder

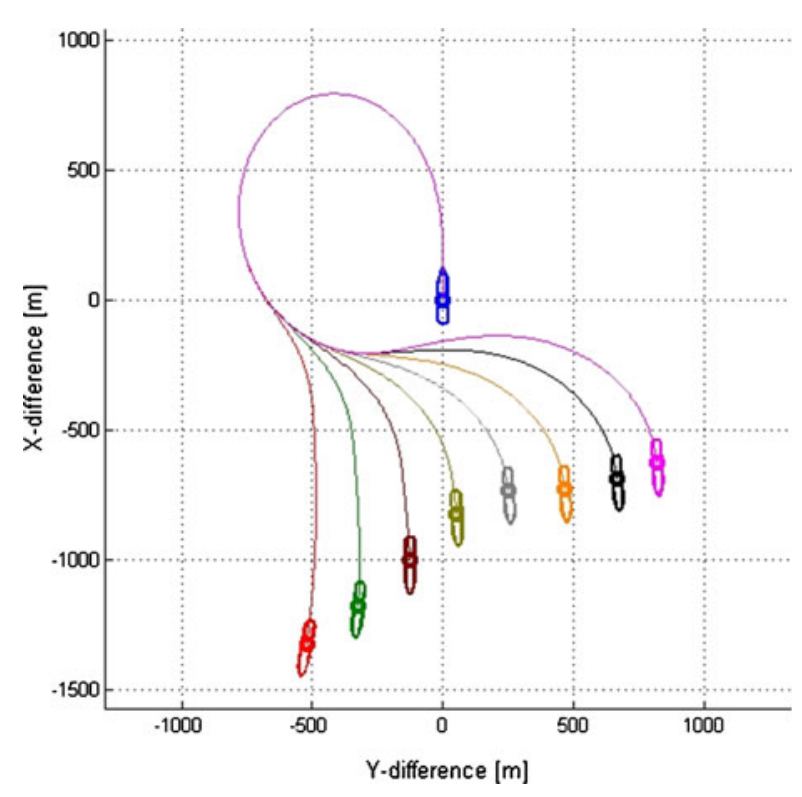

\begin{tabular}{|c|c|c|c|}
\hline Run & $\begin{array}{c}\text { Delta Heading } \\
\text { for Counter } \\
\text { Rudder }\end{array}$ & $\begin{array}{c}\text { Track } \\
\text { Deviation } \\
{[\mathrm{m}]}\end{array}$ & $\begin{array}{c}\text { Course } \\
\text { Deviation } \\
{\left[{ }^{\circ}\right]}\end{array}$ \\
\hline 1 & 200 & 510 & 3 \\
\hline 2 & 210 & 360.2 & 2.4 \\
\hline 3 & 220 & 177.2 & -5.084 \\
\hline 4 & 230 & -16.695 & -7.054 \\
\hline 5 & 240 & -223.248 & -9.485 \\
\hline 6 & 250 & -439562 & -9.417 \\
\hline 7 & 260 & -640.113 & -9.262 \\
\hline 8 & 270 & -794.463 & -9.402 \\
\hline
\end{tabular}

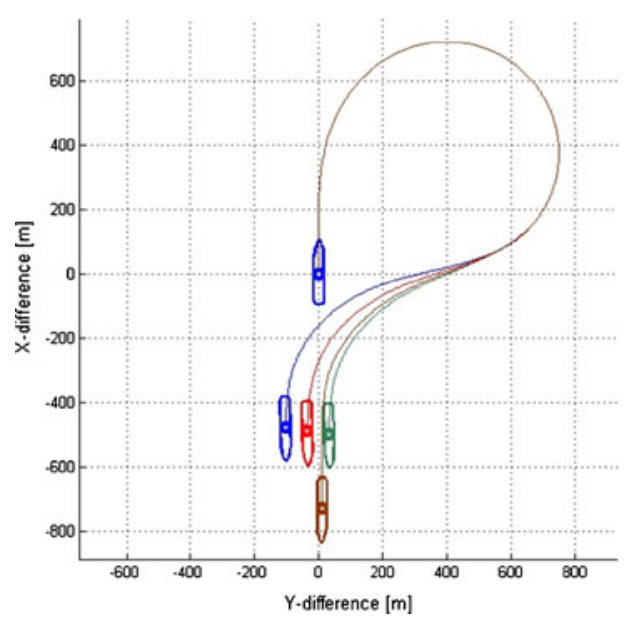

\section{Manoeuvre information}

Main parameter for emergency return manoeuvre with starting speed of $21 \mathrm{kts}$

Type Scharnow Turn

$\begin{array}{ll}\text { rudder hard starboard since } & : 0 \mathrm{~s} \\ \text { course at manoeuvre begin } & : 0^{\circ} \\ \text { duration rudder hard Stb } & : 4 \mathrm{~min} 13 \mathrm{~s} \\ \text { overshoot angle } & : 32^{\circ} \\ \text { opposite course }\left(+180^{\circ}\right) & : 180.0^{\circ} \\ \text { hard counter rudder to portside } & : 4 \mathrm{~min} 13 \mathrm{~s} \\ \text { hard counter rudder to starboard } & : 6 \mathrm{~min} 19 \mathrm{~s} \\ \text { duration till rudder neutral } & : 7 \mathrm{~min} \\ \text { parallel offset } & : 9.2 \mathrm{~m} \\ \text { heading at end of manoeuvre } & : 178.3^{\circ} \\ \text { course at end ot manoeuvre } & : 179.6^{\circ}\end{array}$

Fig. 12 Emergency return manoeuvre optimisation procedure (left) and display of manoeuvring details for optimised steering sequence (right) 
indicated by brown colour in Fig. 10. The main parameters of the optimised manoeuvre procedure are given in the table format.

\section{Summary, conclusions and outlook}

Investigations into the overall situation regarding onboard manoeuvring assistance and into the integration of new maritime technologies onboard ships are performed. The ongoing investigations have shown that there is a potential to increase the operational safety in shipping.

Taking into account the availability of new technologies and new equipment, situation-dependent manoeuvring information should be provided to the navigators on the bridge rather than continuing to provide them with static manoeuvring data which often are incomplete and inconvenient in use. For these purposes, the introduction of a dynamic wheelhouse poster and an electronic manoeuvring booklet is suggested, to provide ship's command with up-to-date information about the manoeuvring characteristics of their ship, adapted to the prevailing environmental conditions.

A concept is developed and exemplarily applied in order to support the accomplishment of manoeuvring tasks in case of a person overboard accident. The fundamental element of this concept is based on innovative fast-time simulation technologies. It is applied for the purpose of providing situation-dependent manoeuvring data by taking into account actual environmental conditions and actual ship status information. The use is also demonstrated exemplarily for the generation of optimised situation-dependent manoeuvring plan for an emergency return manoeuvre.

Future investigations, i.e. will deal with enhancement and validation of suitable visualisation of the fast-time simulation results to support decision making in an ECDIS environment. Therefore, human factor-related investigations dealing with a user-centred design of the human-machine interface have to be performed. Additionally, investigations into the application of the concept on other situations will be carried out.

Acknowledgements The investigations and some of the preliminary results presented in this paper were partly carried out and achieved within the Swedish-German research and technical development project ADOPTMAN which belongs to the MARTEC programme supported by the European Commission. The ADOPTMAN project is funded and supervised by the Swedish Governmental Agency for Innovation Systems (VINNOVA) and the German Research Centre Jülich (PTJ). Furthermore, some parts of the work were carried out within the "Research port of Rostock" which is an initiative supported and funded by the Ministry of Education and Research of Mecklenburg-Pomerania.

Disclaimer The views expressed in this paper are the views of the authors and do not necessarily represent the views of IMO, WMU, or the national authorities.

\section{References}

Baldauf M, Benedict K, Fischer S, Motz F, Schröder-Hinrichs J-U (2011) Collision avoidance systems in air and maritime traffic. In: Proceedings of the Institution of Mechanical Engineers, Part O: Journal of Risk and Reliability, September 2011 vol. 225 no. 3: 333-343. Sage, London. doi:10.1177/ 1748006X11408973 
Baldauf M, Benedict K, Fischer S, Klaes S, Schröder J-U, Wilske E (2011b) Advanced maritime technologies to support manoeuvring in case of emergencies - a contribution to e-Navigation development. In: Weintrit A (ed) International Recent Issues about ECDIS, e-Navigation and Safety at Sea-Marine Navigation and Safety of Sea Transportation. Taylor \& Francis, London, pp 27-34. ISBN ISBN978-0-415-69112-3

Baldauf M, Benedict K, Gluch M, Kirchhoff M, Schröder J-U (2010) Enhanced simulation technologies to support maritime operational risk management onboard ships. Journal of Marine Technology and Environment 3(1):25-38

Benedict K, Baldauf M, Felsenstein Ch, Kirchhoff M (2006a) Computer-based support for the evaluation of ship handling exercise results. WMU Journal of Maritime Affairs 5(1):17-35. doi:10.1007/ BF03195079

Benedict K et al (2006b) Combining fast-time simulation and automatic assessment for tuning of simulator ship models. In: MARSIM-International Conference on Marine Simulation and Ship Manoeuvrability, Terschelling, Netherlands, June 25th-30th Proceedings, M-Paper 19, pp 1-9

Benedict K, Baldauf M, Fischer S, Gluch M, Kirchhoff M (2009) Manoeuvring prediction display for effective ship operation on-board ships and for training in ship handling simulators. In: IAMU 10th Assembly \& Conference 2009 St. Petersburg/Russia at AMSMA, 19-21 September, 2009

Benedict K, Hilgert H (1986a) Returning a ship in the case of person overboard accidents. Part 1. HANSA, Hamburg (in German)

Benedict K, Hilgert H (1986b) Optimising man-overboard manoeuvres. In: 15th Conference of Bulgarian Ship Hydrodynamic Centre, Varna, Proceedings vol. 1, 1986

Graff J (2009) e-Maritime: a framework for knowledge exchange and development of innovative marine information services. WMU Journal of Maritime Affairs 8(2):173-201. doi:10.1007/BF03195159

Hahne J (ed) (2006) Handbuch Schiffssicherheit. Seehafen, Hamburg. ISBN 3-87743-815-6

IMO (2007) Revised performance standards for integrated navigation systems (INS). MSC.252(83). International Maritime Organization, London

IMO (2009) Development of model procedure for executing shipboard emergency measures. STW 41/12/ 3. International Maritime Organization, London

Jutrovic I (2010) Man overboard. Seaways (2010) February, pp 3-4

Schröder-Hinrichs J-U, Baldauf M, Ghirxi KT (2011) Accident investigation reporting deficiencies related to organizational factors in machinery space fires and explosions. Accid Anal Prev 43(2011):11871196

Lloyd M (2007a) Man overboard. 1: Preparation. Seaways (2007) April, pp 22-24

Lloyd M (2007b) Man overboard. 2: Executing the plan. Seaways (2007) May, pp 27-28

Motz F, Dalinger E, Höckel S, Mann C (2011) Development of requirements for communication management on board in the framework of the e-Navigation concept. In: Weintrit A (ed) International Recent Issues about ECDIS, e-Navigation and Safety at Sea-Marine Navigation and Safety of Sea Transportation. Taylor \& Francis, London, pp 27-34. ISBN ISBN978-0-415-69112-3

Weintritt A (2010) Telematic approach to e-Navigation architecture. In: Mikulski J (ed) Transport systems telematics, communication in computer and information science, vol 104. Springer, Heidelberg, pp 1-10. doi:10.1007/978-3-642-16472-9 1

Weintrit A (2003) Voyage recording in ECDIS. Ship-borne simplified version of voyage data recorders (VDRs) for existing cargo ships based on potential of ECDIS. In: 11th IAIN World Congress 'Smart Navigation-Systems and Services', Berlin, pp 21-24 October 